\title{
The inner life and structure of ESHG
}

\author{
Gunnar Houge and Jerome del Picchia* \\ European Journal of Human Genetics (2017) 25, S16-S19; doi:10.1038/ejhg.2017.144
}

The European Society of Human Genetics is a non-profit organisation registered in Belgium with its administration in Austria at the Vienna Medical Academy (VMA). The foundations, legally responsible for the organisation of the conferences, are based in The Netherlands. This division of legal, economical and administrative roots is a challenge. ESHG's core is the Board and the base is the membership. The Executive committee belongs to the Board and is the unit that takes care of daily administrative matters. ESHG has many committees (see www.eshg.org), some more active than others. We have only one employee; a half-time paid professional conference-and-everythingelse organiser. This is the executive officer (EO). He has become an essential person for the whole society.

\section{THE EXECUTIVE COMMITTEE (THE EXEC)}

The Exec and Board can be thought of as the government and parliament of ESHG. The Exec consists of six elected members+the EO. These members are the three presidents (president elect, president and vice president), the general secretary, the deputy general secretary and the treasurer. The presidents are in the Exec for three years before being transferred to the Board for two more years after the end of Exec service. Thus, a president is president for only one year, which ensures frequent renewal.

The presidents can be thought of as the political part of the Exec, nominated by the Board and endorsed by the membership following suggestions by the Board or the membership. Other Exec members are elected by the Board after the suggestion of candidates by the Exec/ Board. The term for the administrative officers (the general secretary, deputy general secretary and treasurer) is three years with a possibility of renewal; after end of their term they do not become Board members. In reality, the general secretary, deputy general secretary and treasurer are usually there for at least six years, and together with the EO they can be thought of as the administrative part of the Exec, with knowledge of how to take care of all daily matters. The Exec has three regular meetings per year: one just ahead of the ESHG annual meeting, one just ahead of the ASHG annual meeting, and the last is in Vienna where our EO works with his team from Vienna Medical Academy (VMA). VMA is our conference organiser, and also the body administering the Membership, fellowship applications, and many of the committees.

\section{THE BOARD}

The current Board has 25 members, and rules have been made to avoid dominance by a single country and to ensure a balanced representation of gender and age. Whether these new rules achieve their goals remains to be seen, but Board elections appear less random than before. The Board has also been opened to overseas members, currently one from Australia and one from the US. There are just two regular Board meetings: The major meeting takes place on the day before the ESHG annual meeting, and then there is a short meeting within the ESHG annual meeting (the meeting of the new Board). There is also an Executive meeting open for Board attendance at the ASHG annual meeting. The most important task of the Board is to follow and control the Exec. The Board members receive Exec minutes, and they are encouraged to promote issues for Exec/Board discussion. If Board members disagree with Exec decisions, they can say so, and the issue will be raised for discussion at the next Board meeting if not before. The Exec should pass all questions of major political or economic importance through the Board before reaching decisions.

Board members are also encouraged to take part in committee work - which sometimes may be a little difficult since many committees recruit their own members and vacancies are few. This is a problem that needs addressing in the future. Board members have also successfully performed tasks on behalf of the Exec, for example, EuroGentest evaluation after the end of EU support which resulted in EuroGentest integration into ESHG, and a thorough evaluation of our web-site before the current restructuring and new web page design.

Another important task of the Board is the endorsement of ESHG documents, usually prepared by the Public and Professional Policy Committee (PPPC), sometimes by EuroGentest, and sometimes as a result of collaboration between ESHG and other societies (like ESHRE). PPPC has made a written procedure for ESHG endorsement of policy documents. Most of these policy documents are later published in our journal.

\section{THE COMMITTEES}

The committees may initially appear to be a somewhat confusing part of ESHG. They lived, and partly still live, their own life. The structure is, however, clearer than before. To avoid confusion, it should be stated at the outset that the European Board of Medical Genetics (EBMG) is not an ESHG committee but a legally independent body issuing certificates for professionals; see www.ebmg.eu for more information. ESHG fathered (see above) and still strongly supports this organisation, and EBMG administration is done in collaboration with VMA.

\section{ANNUAL MEETINGS COMMITTEE (AMC)}

This is chaired by the treasurer and consists of the Exec and chair of the Scientific Programme Committee (SPC) with advisors from Vienna Medical Academy (VMA) and Rose International. Rose International looks after all the commercial aspects of the annual meetings, for example, renting floor space to exhibitors, arranging commercial satellite meetings and selling advertisement space and 
items. The annual meetings have to be planned well ahead of term, and currently we try to schedule meetings at least five years ahead.

\section{SCIENTIFIC PROGRAMME COMMITTEE (SPC)}

This is our most important committee, and its success is imperative. To arrange excellent annual meetings remains the major activity and goal of ESHG. Without a successful conference, the Society would not survive.

The SPC consists of about 23 members plus two observers from the Exec and two observers from EMPAG in non-EMPAG years. Every second year the ESHG conference is arranged together with EMPAG (European Meeting on Psychosocial Aspects of Genetics), and then the EMPAG representation in the SPC is strengthened a little. Some members, usually four, are 'locals', that is, representing the host country/countries (as with Scandinavia this year). SPC terms are for four years, an exception to the general three-year rule. The chair sits for two years (renewable), and chairs usually have longer SPC experience than four years. Members are selected based on scientific merit, scientific profile (all major aspects of human genetics should be covered) and geographical origin. The SPC should be representative and balanced, reflecting the whole of Europe and the different age groups and professions. The SPC should have knowledge in all areas of human genetics, and members must be well informed on current trends and be active scientists working in scientific networks.

It is a hard-working committee with two important meetings per year: One about a month after that year's annual meeting, and one in the middle of March in Vienna. At the first meeting, invited speakers for the next year's annual meeting are suggested and decided upon based on theme/subject proposals made by SPC members. All SPC members should submit proposals for scientific and educational sessions ahead of this meeting. In addition, workshops are planned. At the meeting in March, abstracts are selected for platform presentations (usually $4-5 \%$ of the total). These abstracts have been judged and graded by SPC members and external evaluators from Board and Membership ahead of the meeting. Finally, a detailed programme is put together consisting of platform presentations, concurrent symposia and educational sessions, all with invited speakers, and concurrent sessions based on the best abstracts. In addition, there are the workshops and corporate satellites.

The only meeting-related and really important activity that the SPC does not control is the conference party. This is a get-together activity for attendees of all ages, and everybody wants this to be a feel-good experience unique to our meetings.

\section{PUBLIC AND PROFESSIONAL POLICY COMMITTEE (PPPC)}

This committee of approximately 14 members produces policy documents on behalf of ESHG. Depending on the subject, other contributors may be asked for assistance. The committee has produced one or two such documents each year for many years, and after feedback from the membership and the Board (usually on our web site), most of these documents are passed through the Board for endorsement before publication in our journal. The PPPC is often consulted by the Exec on current policy matters, for example, the Kuwait suggestion to DNA test all inhabitants and visitors, and the current US bill that will allow economical penalties on employers opting out of predictive genetic testing related to health insurance. Policy statements are often drafted by our long-term collaborating scientific journalist, Mary Rice, and passed through the PPPC chair and Exec for final approval before being issued as a press release and put on our web site.

\section{EDUCATION COMMITTEE (EC)}

This committee has recently been restructured, and now consists of four arms dealing with the ESHG course portfolio, the DNA day, the schoolchildren event related to our annual meeting, and educational materials. It is a committee of growing importance, especially since it is an aim of ESHG to provide courses and educational material that can be used for professional training of genetic counsellors/nurses, clinical laboratory geneticists (CLGs) and medical/clinical geneticists.

\section{ESHG-EUROGENTEST COMMITTEE}

EuroGentest has recently been 'adopted' by ESHG, and the major activity has so far been a preconference satellite meeting or an annual conference workshop. Plans are ambitious, and many activities are still under development. One exception is quality matters, that is, questions related to external quality assessments. The previous Quality committee is now part of ESHG-EuroGentest, and they have regular meetings.

\section{THE EUROPEAN HUMAN GENETICS CONFERENCE}

The annual meeting of ESHG (with the Dutch conference foundations as organiser) remains the biggest task of the year. Until 2001, the meeting moved between 30 cities in Europe, as did the respective conference secretariats. To arrange the International Congress of Human Genetics 2001 (ICHG 2001) in Vienna, Gerd Utermann, former ESHG president, contacted the Vienna Medical Academy (a medical non profit association, just like ESHG) and entrusted them with the organisation of the meeting. Jerome del Picchia was the first project manager; this happened, in fact, by pure coincidence, as he stepped in on rather short notice for a colleague who left the VMA in the preparation phase of ICHG 2001.

The ESHG was satisfied with the organisation of the 2001 conference and signed a long term contract with the VMA as of the 2002 conference in Strasbourg.

The exhibition and sponsoring management was contracted to ROSE International, a company based in The Hague, The Netherlands. They have been responsible for the organisation of the corporate exhibition, the corporate satellites and the sponsorship since ESHG 1998 in Lisbon.

Since then, a younger generation of professionals has joined the organising team: Kristina Libova, Mirjam Uebelhör and Flora van Laer have added their spirit and fresh ideas. The SPC chairs of the last 17 years (Andrew Read, Han Brunner, Brunhilde Wirth and Joris Veltman), have contributed their distinct character to the task and have each laid their own cornerstones, making the conference into what it is today.

Consequently also the congress has changed its livery in the past 17 years. The most obvious change is surely the impressive increase of attendees. As the records of the pre-2000 s are rather fragmentary, reliable numbers are only available for the 'VMA era'. Obviously the extra-ordinary ICHG meeting in 2001 gathered an impressive number of more than 2700 delegates from all over the world, but the reality of the ESHG meetings of the time was a different one.

The first regular meeting to pass the 1000 active participant threshold was London in 1996. From 2001, with the exception of the Birmingham meeting in 2003, which showed a decrease to pre2000 numbers, all meetings constantly attracted over 1400 attendees. The first conference to pass the 2000 was Barcelona in 2008, the first to pass 3000 was Paris in 2013, culminating in Barcelona (again!) in 2016 with over 3400 active participants.

So the ESHG has more than tripled its meeting attendance in the past 17 years. Similarly, the number of abstract submissions doubled 
between 2002 (1386 in Strasbourg) and 2016 (2728 in Barcelona). In terms of exhibitors the numbers are almost as spectacular: from 75 exhibitors in 2002 to 154 in 2016. This evolution has made the ESHG meetings into the second biggest human genetics conference in the world after the American Society of Human Genetics (ASHG) meeting.

We have witnessed another obvious change in the programme structure over the years. In 2002, one time slot had a maximum of three concurrent symposia (invited lectures), concurrent sessions (from submitted abstracts) or workshops. Today the programme grid accommodates up to seven workshops, six concurrent sessions, six concurrent symposia and educational sessions at any given time. The educational sessions were introduced in 2005 by former SPC chair Han Brunner after a suggestion by Ulf Kristofferson, in order to offer high quality overviews of various topics to a general audience. Consequently, the number of invited speakers has equally doubled between 2002 (42) and 2017 (85).

These numbers mean increasing difficulty in finding a suitable conference centre able to accommodate seven to eight lecture halls, five halls for corporate satellites, four rooms for ancillary meetings and sufficient space for up to 160 exhibitors, over 1,600 posters and the required spaces for coffee breaks, registration etc., while remaining logistically compact and affordable within the budget of a meeting that does not have the support of the pharmaceutical industry.

Despite the challenge of working with a budget that is not comparable to those of the typical clinical specialities, the European Human Genetics Conference has introduced a number of enhancements along with the constant evolution of technology over the years. While WiFi was a 'luxury' in the beginning of the $2000 \mathrm{~s}$, it has become a sine qua non very quickly. Still, one would be surprised to learn how many conference centres in Europe that are still massively underequipped for the number of mobile devices needing internet access that an average attendee carries today.

The constant use of the internet during a conference, the mobile conference app, which the ESHG developed back in 2012, the online programme planner, voting in interactive sessions, social media platforms like Twitter on which participants exchange intensely during the talks, and obviously, emails and short message applications that allow one to remain in touch with work and loved ones while abroad, can turn a non-working WiFi into a disastrous experience.

In recent years, our meeting was upgraded with items like the live transmission of selected sessions in the exhibition area, creating an 'overflow area', hence making crowded sessions less of a hassle. Educational sessions, joint symposia with other societies and plenaries are now available as either live- or on-demand webcast. More recently, electronic poster presentations have also been introduced to be able to cope with the increasing number of accepted papers. In 2017, for the first time, the 20 best rated posters were presented electronically in the E-poster area and as short 'teaser-presentations' in one of the concurrent sessions.

The SPC has equally focused on including a larger number of young investigators, both within the committee itself and at the conference by inviting recent Young Investigator Award Winners to co-chair a session, by offering workshops aiming at career-development, and by increasing the number of awards and fellowships offered to young investigators.

Finally the ESHG congress parties have become somewhat legendary events and it is the society's policy that the hard working genetic community deserves most enjoyable and well lined-up Monday evenings.

All these additions coincided with reductions in other areas borne out of a growing responsibility towards resources, our environment and sustainable conference material. In addition to choosing a larger number of items from recycled or sustainable sources (pens, bags, lanyards etc.), the ESHG stopped printing an abstract book in 2011. This publication, nowadays totalling $700+$ pages, would mean over 6 tons of ink and paper produced each year. This bold step was counterweighted by the increased provision of electronic and online availability of the abstracts and seems to have been well accepted by the community. While the 'paperless conference' is not yet a reality, we have been able to reduce the amount of paper produced for our meeting by over $50 \%$ compared with eight to ten years ago. This includes also a number of 'behind the scenes' measures, which were implemented in the administration process and represent money the ESHG can now spend on other conference budget items.

It may not be widely-known that the ESHG conferences are not arranged to generate a profit for the society (in line with the main goal of a non-for-profit association). Fortunately, the European Journal of Human Genetics, guided by the Editor in chief Gertjan B van Ommen and published by SpringerNature, has become a fixed value in the landscape of genetic journals with its impact factor of 4.580 and is an indispensable asset of the ESHG. The ESHG profit share, along with the membership fees, allows the society to run its usual activities over the year. So as an attendee, one can be assured that the budget raised by conference fees, sponsorship and the exhibition, is actually reinvested in the conference and the experience of the delegates. At the same time, the ESHG needs to watch the budget carefully to avoid the regular draining of the reserves, while still continuing to improve the meeting.

This delicate balancing act is made possible through to the unique combination of a highly focused SPC, having free rein in their endeavour, a long term congress organiser sharing the 'non-profit DNA' of ESHG, and a highly dedicated 'for profit' exhibition and sponsorship management, building a professional whole, focusing on scientific excellence and constant improvement in an atmosphere of mutual trust and reliability.

Gunnar Houge and Jerome del Picchia

Dr Gunnar Houge, Center for Medical Genetics, Haukeland University Hospital,5021 Bergen, Norway.

Tel: +47 5597 5475;

E-mail: houge@helseergen.no

Mr Jerome del Picchia, Executive Director, ESHG c/o Vienna Medical Academy, Alser Strasse 4, 1090 Vienna, Austria. Tel: +43 140513 822; E-mail: eo@eshg.org 


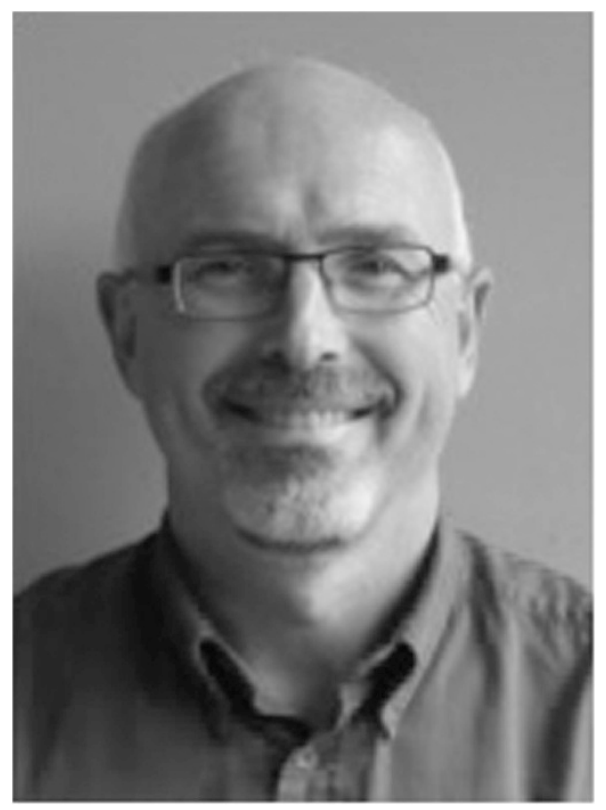

Gunnar Houge $\mathrm{MD}, \mathrm{PhD}$, is a diagnostic genetics laboratory director, senior consultant in clinical genetics, and part time professor at the Department of medical genetics at Haukeland University Hospital in Bergen, Norway. He started his clinical genetics career in 1996, after having done basic research on cAMP-dependent protein kinase, apoptosis and ribosomal RNA for 10 years. He has also worked part time for 12 years as a general practitioner in a small and remote community in Norway, just north of the polar circle. Current research focus is on new syndromes, causes of autism and intellectual disability, and structural genomics. In 2008 he became deputy general secretary of ESHG, later on general secretary (for 6 years), and in 2017 he was nominated and approved as ESHG president elect for 2018.

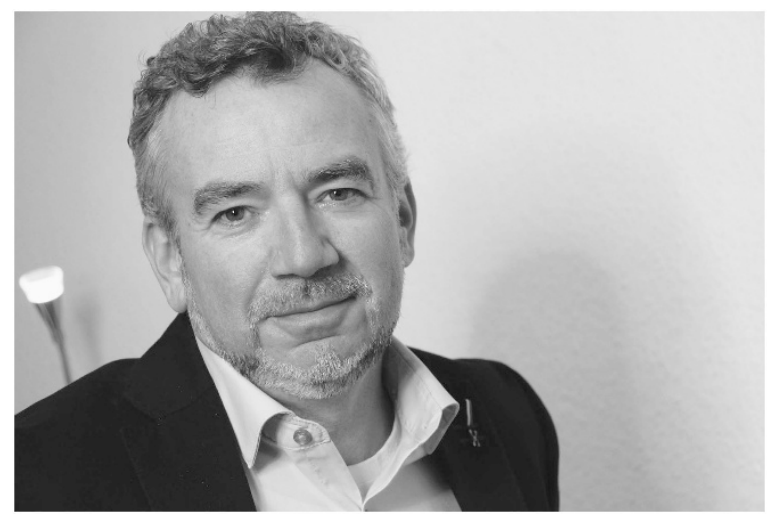

Jerome del Picchia is the Executive Officer of the Society of Human Genetics. Born in 1969 in Vienna, Austria, the bi-national (French \& Austrian) has been working as a conference manager with the Vienna Medical Academy since the early 1990ies, where he became responsible for the organisation of the ESHG meetings in 2000 for the ICHG 2001. In 2007, during his ESHG presidency, Sir John Burn was aiming at a professionalisation of the administrative side of the ESHG. Having been involved in the ESHG conferences for many years, Jerome del Picchia was the obvious choice for the task of the newly created position of Executive Officer and is since then supporting the Executive Board in its duties. Due to his strong background in Scientific Management as a Professional Congress Organiser, he is also a liaison to the SPC and supervising the conference organisation performed by the Vienna Medical Academy, a Vienna based non for profit association specialised in conference and association management.

Jerome del Picchia lives and works in Vienna is married to a lawyer and is a father of two. 